\title{
Shaanxi Somewhere Dangerous House Static Pressure Pile in Reinforcement Engineering Design and Support

\author{
Xiao Qiang Wu
}

(yanan university construction engineering school, shaanxi yanan, china716000)

Email:nwwolf197724@163.com.

Keywords: Strip foundation; Reinforcement; Static pressure pile; Design; The Supporting

\begin{abstract}
: by means of static pressure pile reinforcement technique of shanbei somewhere masonry structure reinforcement strip foundation, can improve the bearing capacity of foundation, the foundation settlement stabilized, meet the bearing capacity of normal use and use requirement. At the same time introduces the reinforcement principle of static pressure pile, construction method and matters needing attention, the construction quality control and its reinforcement effect, provides reference for similar regional static pressure pile reinforcement.
\end{abstract}

\section{The introduction}

High bearing capacity, the static pressure pile quality has very good guarantee, and the construction noise and vibration are small, no slurry pollution environment, short construction period, the pile driving fast. Due to the advantages of the many, in the construction and expansion project, static pressure pile has been widely used. In the process of dangerous house foundation reinforcement, static pressure pile in the process of foundation reinforcement technology has also got very good application[1 6].

\section{The static pressure pile penetration and compaction effect on pile driving mechanisms}

Static pile penetration of compaction mechanism. When static pressure pile construction adopts the special frame weight and weight or the weight of the structures, through the whole pile pressure beam or column or the weight of the structures of balancing deadweight and reaction, and applied in hydraulic hoist pulley block or electric pump way at the top of the pile or pile body, when applied to the static pressure pile and soil resistance of pile of dynamic balance, pile in weight or pressure under the action of static pressure gradually into the foundation soil. Pressure during pile, pile rate generally remain within a certain value, so the pile penetration can be regarded as uniform motion in a straight line. Static pressure pile in the process of penetration caused by complex of movement, under the pile tip soil compression deformation. With the increase of pile penetration pressure, when the pile tip pressure exceeds the shear strength of soil, sharp deformation and failure of soil, the pile side soil plastic flow occurs (clay) or lateral compaction and towing sinking soil (sand), soil under the pile tip was downward and lateral compression is open. Surface area, mainly to the pile of viscous soil mass under weeks apart, keep close to the pile soil structure destroy completely, also affected by the bigger disturbance of soil around the pile body is a powerful method to soil resistance caused by the friction of pile and pile tip resistance of the resistance. At the same time, the saturated cohesive soil, due to the instantaneous drainage consolidation effect is not obvious, the pile penetration of pore water pressure, pore pressure dissipation, and consolidation and thixotropic recovery, in pile form shell layer. For static pressure pile, due to its nearly uniform in the process of penetration, therefore, in theory, the quasi static static equilibrium under the condition of appropriate to its simulation[7 8].

Static pile pile mechanism. Expansion theory is the main research methods for static pressure pile on international. Expansion theory first assume that the soil is the ideal elastic-plastic body, materials obey Treasa or Mohr - Coulomb yield criterion, according to the theory of elastic-plastic body give infinite soil body, has the initial radius of bore cylindrical or spherical, uniform distribution of internal pressure $\mathrm{p}$ is expansion of the general solution. Due to the pile penetration 
trendy, radius of certain depth in the soil gradually appear as the diameter of holes, a range of soil around into the plastic state, therefore, generally cylindrical cavity expansion is used to simulate remove near the deformation of the pile end and pile tip. Butterfield and Baneriggee prime minister under the condition of plane strain is proposed to cylindrical cavity expansion is used to solve the problem of pile penetration. They assumed that: (1) the soil is homogeneous and isotropic ideal elastic-plastic material; (2) soil saturation, incompressible; (3) the soil yield meet Mohr - Coulomb strength criterion; (4) the holes before the expansion, the soil with the effective stress to the equivalent. With the increase of internal pressure $\mathrm{p}$, cylindrical hole around the bar area will by elastic state into plastic state. Rising in the plastic zone is increased and the p, outside the soil remains elastic state. For axisymmetric plane strain problem of the cylindrical cavity expansion, under the polar coordinate. For the equilibrium differential equation

$$
\frac{d \sigma_{r}}{d r}-\frac{\sigma_{r}}{\sigma_{\theta}}=0
$$

The plastic on the border to meet Mohr - Coulomb yield criterion

$\sigma_{r}-\sigma_{\theta}=2 c_{u}$

Boundary conditions are as follows: $r=R_{u}, \sigma_{r}=p_{u}$

According to the principle of volume of soil, the solution of the differential equation, launch, and the radial displacement of expression, the pressure caused by pile instantaneous excess pore water pressure, pore pressure, the use of the henckel equation is derived:

$\square u=\beta \sigma_{D}+\alpha \square \tau_{D}$

Sagaseta application semi-infinite space spherical cavity expansion theory and found the surface horizontal displacement and vertical uplift quantity calculation formula:

$$
\begin{aligned}
& S_{H}=\frac{2}{3} a^{3} \frac{L}{R^{2}+\sqrt{R^{2}+L^{2}}} \\
& S_{V}=\frac{2}{3} a^{2}\left|\frac{L}{R}-\frac{L}{\sqrt{R^{2}+L^{2}}}\right|
\end{aligned}
$$

Type: the radius of the said pile; Said the pile capacity; Said to calculate the distance from the pile axis; The horizontal displacement and uplift, respectively ${ }^{[9,10]}$.

\section{Design reinforcement scheme}

Project summary. The project designed by the village committee and the construction unit, construction procedure is not standard, there is no formal drawings. Two-story brick structure, every three studio ( $3 \times 3.6 \times 10$ ), a building area of $216 \mathrm{~m} 2$, hutch, defend, hall, a layer set indoor stair hall, brick strip foundation, the width of $500 \mathrm{~mm}$, lower berth 300 thick 3:7 lime soil cushion, width $1.0 \mathrm{~m}$, water, electricity, warm professional supporting is not complete, in front of the road and drainage, greening by village committee unified planning.

Project started in July 2009, July 2011 subjects completed, no government quality, by a representative of the village committee to monitor the construction process, in December 2011 found the first few rows of houses in the west of uneven settlement of foundation, some outside longitudinal wall inclined cracks, west of the distance from the houses built having groove have multiple cracks, judging by the terrain, the cracks continue to grow.
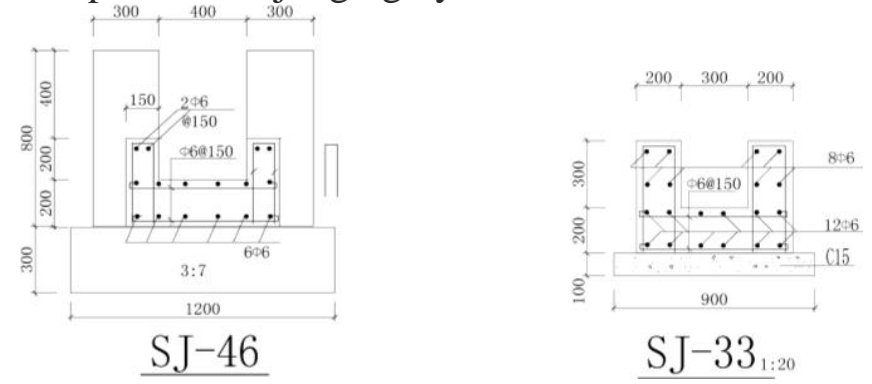

Figure. 1 the drain 


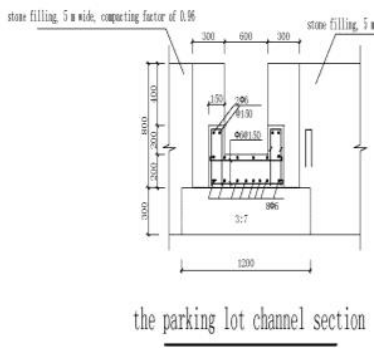

Figure. 2 channel section

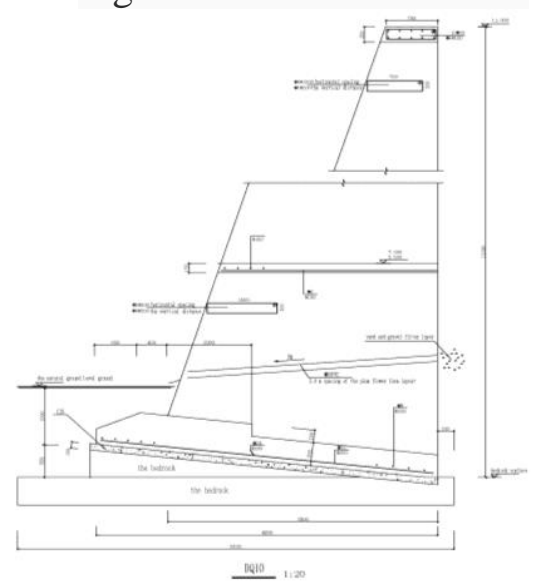

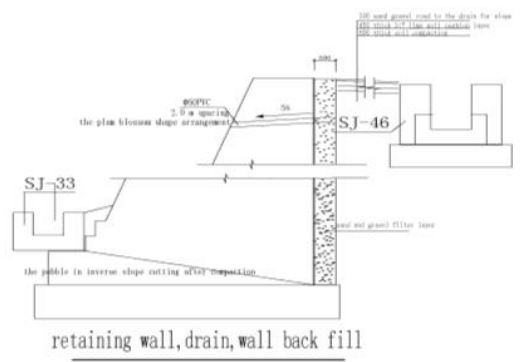

Figure. 3 retaining wall, drain, wall back fill

Figure. 4 retaining wall section

The foundation settlement and wall cracks circumstances: Geomorphic units of construction sites with a gentle slope on the loess plateau gully, the terrain is open, the original state of farmland, site with two small gully, part of the bedrock outcrops, the crack line slope and to the mountain, covering the maximum thickness of $7.0 \mathrm{~m}$, the west has a deep " $\mathrm{V}$ " shape use a ditch, rain erosion cutting for a long time, steep walls, human activities are natural at the bottom of the groove, as the expansion of construction land, the artificial digging filling regulation did not undertake unity when rolling, soil degeneration, rely on natural consolidation, with the filling thickness variation in different subsidence deformation, project performance is poor, potential harm is big, easy create housing inhomogeneous deformation of foundation. Rows at the end of 2011 found that the west is relatively close to gully edge building foundation uneven settlement, the longitudinal wall produces a few diagonal crack, Windows and doors hole in stress concentration phenomenon is obvious, crack wider, most of the crack width of $5 \sim 12 \mathrm{~mm}$, subgrade settlement deformation, wall cracks to dig fill feature perfectly match with the original landform.

Static pressure pile construction. track test pile: before the static pressure pile construction, about 6000 range from building pressure into the first three piles, jack not more than $45 \mathrm{mpa}$ pressure readings, guarantee the pile tip into the layers of about $1000 \mathrm{~mm}$, two days after the start loading test pile, and inform the design, the prospecting units to join. Temporarily consider the single pile vertical ultimate bearing capacity standard Quk $=500 \mathrm{kn}$, single pile vertical bearing capacity characteristic value of $\mathrm{Ra}=250 \mathrm{kn}$. Test pile biggest load of $620 \mathrm{kn}$ or less, the project can be instead of test pile. Pile length $10 \mathrm{~m}$, finally determine when pile test report out. Static pressure pile construction process flow diagram is shown in figure 2.

material: steel tube concrete JYZ 168-6,1.2, pile cap closed for C30, pisolite concrete pile caps and ground beam bottom gap with dry hard C40 pisolite concrete fill in (expansive cement). Steel bar, steel plate, Angle of A3 steel.

\section{Conclusion}

The project according to the structure of the structural characteristics, environmental conditions and geological conditions, using static pressure pile reinforcing foundation, has obtained the good economic and social benefits, the investment is saved, and meet the requirements of the use 
function, to guarantee the normal life;

In a brick house, through the use of static pressure pile, can effectively solve the uneven settlement of foundation, strengthening effect is good.

\section{References:}

[1] H.M. Su, Static Pressure Precast Pile Influence on Surrounding Buildings and Countermeasures [J]. Architectural technology development, 2000, 27 (6) : 8-9. (In Chinese)

[2] H,R, Zhou, Soil Mechanics and Foundation Engineering [M]. Wuhan: Wuhan university of technology press, 1988(In Chinese)

[3] Z.X. Li, Method and Its Application in Static Load Pile Test [J]. Architectural technology, 2000, 31 (3) : 157-159. (In Chinese)

[4] X.N. Gong. Soil Nailing and Composite Soil Nailing Support Several Problems [J]. Journal of civil engineering, 2003, 4 (10) : 80-83. (In Chinese)

[5]GB50021-2001, the Geotechnical Engineering Specification [S]. Beijing: China building industry press, 2009. (In Chinese)

[6] GB50007-2010), the Building Foundation Design Specification [S]. Beijing: China building industry press, 2011. (In Chinese)

[7] G.Q. Luo. Masonry Structure [M]. Changsha: hunan science and technology press, 1993.

[8] DZ/T 0219-2006, the Landslide Prevention and Control of Engineering Design and Construction Technical Specification [S]. (In Chinese)

[9] GB 50330-50330, the Building Slope Engineering Technical Specifications [S].

[10] J.P. Ma. Static Pressure Pile Underpinning Technology in the Application of Equipment Foundation Reinforcement [J]. Architectural technology, 2000, 31 (8) : 548-549. (In Chinese) 